\title{
Insurer and Employer Views on Pediatric Obesity Treatment: a Qualitative Study
}

\author{
S.E. Hampl ${ }^{1,2}$, A.M. Davis ${ }^{2,3}$, M.L. Sampilo ${ }^{4}$, K.L. Stephens ${ }^{1}$, and K. Dean ${ }^{3}$ \\ ${ }^{1}$ Department of General Pediatrics, Children's Mercy Hospitals and Clinics/University of MO- \\ Kansas City School of Medicine, Kansas City, Missouri, USA \\ ${ }^{2}$ Center for Children's Healthy Lifestyles and Nutrition, Kansas City, Kansas, USA \\ ${ }^{3}$ Department of Pediatrics, University of Kansas Medical Center, Kansas City, Kansas, USA \\ ${ }^{4}$ Clinical Child Psychology Program, University of KS, Lawrence, Kansas, USA \\ ${ }^{5}$ Department of Nutrition, Children's Mercy Hospitals and Clinics/University of MO-Kansas City \\ School of Medicine, Kansas City, Missouri, USA
}

\begin{abstract}
Objective-The effectiveness of group-based comprehensive, multidisciplinary (stage 3) pediatric weight management programs is backed by a growing body of literature, yet insurance coverage of these programs is scarce to nonexistent, limiting their reach and long-term survival. The objective of this study was to better understand the perspectives of insurers and large employers on the issue of group-based treatment coverage.
\end{abstract}

Design and Methods-The authors performed a qualitative study utilizing structured interviews with these stakeholders, following accepted techniques.

Results-Six major themes emerged: cost, program effectiveness, corporate social responsibility, secondary parental (employee) benefits, coverage options and new benefit determination.

Conclusion-Future efforts to secure payment for group-based pediatric weight management programs should address these key themes.

\section{Introduction}

Pediatric obesity threatens the current and future physical and emotional well-being of $17 \%$ of children and teens nationwide (1). Because obesity acquired in childhood is likely to be maintained into the adolescent $(2)$ and adult $(3,4)$ years, identifying effective options to treat obesity and prevent or improve comorbidities is of utmost importance. Aside from the significant impact on physical and emotional health that obesity poses, it also impacts future

\footnotetext{
(C) 2012 The Obesity Society

Correspondence: S.E. Hampl (shampl@cmh.edu).

Disclosure: The authors declare no conflicts of interest.
} 
employability (5) and salary potential and corporate advancement $(6,7)$ of young adults, particularly females.

In 2007, an expert committee composed of representatives from 14 national organizations, including the American Medical Association and the American Academy of Pediatrics, created recommendations for the assessment, prevention and treatment of child and adolescent overweight and obesity, based on the best available evidence (8). The treatment recommendations specify a four-staged approach, with each successive stage providing a higher frequency and intensity of care. Stages 1 (Prevention Plus) and 2 (Structured Weight Management) are to occur within the primary care provider office, with visits up to monthly in frequency. Stage 3 (Comprehensive Multidisciplinary Intervention) involves weekly individual or group-based visits providing a multidisciplinary (nutrition, physical activity, behavioral) approach for a minimum of 8-12 weeks. Stage 4 (Tertiary Care Intervention) adds bariatric surgery, a very low calorie diet and/or medication prescription to a stage 3 program.

Although there is less empirical evidence available to support the effectiveness of stage 1 and 2 treatment, a moderate and growing body of literature exists supporting stage 3 treatment, especially group-based weekly interventions. Two recent meta-analyses cite numerous published reports from 27 years ago to the present which detail short- and longterm weight loss and improvement of clinical and behavioral parameters following these weekly programs $(9,10)$ and no evidence of harm. The US Preventive Services Task Force gave a grade B recommendation (meaning that the USPSTF recommends the service, that there is high certainty that the net benefit is moderate or there is moderate certainty that the net benefit is moderate to substantial) for clinicians to "screen children aged 6 years and older for obesity and offer them or refer them to intensive counseling and behavioral interventions to promote improvements in weight status" (11). In this statement, based on the Whitlock et al review, moderate to intensive counseling and behavioral interventions were defined as those providing a minimum of 25 contact hours over a 6-month period.

Despite the available and growing evidence of the effectiveness of stage 3 treatment programs, these programs are not considered a covered benefit by the vast majority of health insurers. A recent review of state Medicaid manuals revealed that only 10 states apparently reimburse for obesity-related treatment in children (12). Although a few model coverage schemes have been developed for adoption by commercial insurers (i.e., Alliance for a Healthier Generation's Healthier Generation Benefit (13), which covers four primary care provider and four dietitian visits, most group-based treatment programs remain uncovered. This necessarily limits the sustainability and disseminability of these stage 3 programs, which, often originally supported by research grants, occur in research/pediatric tertiary care settings. Additionally, although federal grants support outcomes research in this area, many community-based funders are shifting provision of their resources towards multi-level policy and environmental change projects, and away from individual- and family-based interventions. Access to empirically supported, effective treatment of obesity and treatment or prevention of comorbidities is thus severely limited for the vast majority of affected children and teens. Faced with these challenges in their own family-based stage 3 group treatment programs in a large Midwestern metropolitan area, the investigators sought to 
understand the perspectives of insurers and medium-large employers on the issue of coverage for these Stage 3 pediatric obesity treatment programs.

\section{Methods}

To identify potential participants from the insurer side, researchers consulted with the managed care departments of their institutions and identified the most common insurers of patients seen for stage 3 obesity treatment. To identify potential participants from the employer side, researchers identified a list of medium- to large-sized corporations through a search of the local business bureau website. Institutional Review Board approval was obtained for the project.

An invitation letter describing the project and the investigators' desire to conduct individual structured interviews was sent to the medical director of 7 health insurers and the benefits director of 11 corporations in Spring 2011. Follow-up telephone calls were made to ensure receipt of the invitation letter and to schedule the interview. Interviews were conducted at insurer and employer offices by the same two investigators, one of whom is an experienced qualitative researcher. Two interviews were conducted by only one investigator. The majority of interviews were audiotaped (with permission), but one benefits director declined for the interview to be audiotaped. After a consent paragraph was read by one of the investigators, interviews followed a semistructured format, based on 10 grand tour questions, with follow-up questions as needed determined by the investigators (Table 1). Questions were derived based upon the first two authors' previous experience with pediatric obesity insurance coverage issues and literature review. Specifically, questions were designed to be conversational, clear, seek help from participants, and allow sufficient time (14). Interviews lasted from 20 to 75 min depending upon interviewee responsiveness. Insurer and employer interviews were continued until saturation was reached. The audiotapes were transcribed by an administrative professional who was otherwise independent of the project. Three trained individuals independent of the interview process each reviewed the transcripts and identified the major themes, according to the techniques of Morgan and Krueger (14). The identified major themes were reviewed with the principal investigator and consensus was obtained. Using these identified themes as a guide, the three individuals then recoded the transcripts deductively. Supporting quotations were identified to accompany each major theme. These methods are well validated as being ideal for analyzing focus group and structured interview data (14).

\section{Results}

Five health insurer medical directors and six employer benefits directors (including 1 health insurance broker) were interviewed before saturation was reached. Over $50 \%$ of employers were self-insured. Six major themes emerged.

\section{Theme 1: Cost is a major issue and programs that are cost-neutral would be favored}

The issue of cost was the first identified theme, with both insurers and employers reporting increased costs of healthcare and desire to control expenditures. This finding was not surprising given the current political and media focus on the cost of healthcare. As one 
participant reported, "Our health care costs are going up very quickly and we are trying to get a handle on why." Another stated, “...right now, cost is an area that they [employers] are really challenged with, with all the other issues going on and the economy, so that's a 'top of mind' for them." Specifically, participants were interested in information on the costs associated with pediatric obesity that are accrued in childhood, since by the time most children reach adulthood they are highly likely to change insurance providers. They were also interested in the direct costs associated with stage 3 treatment programs, or what the charge would be per participant. Return on investment was another key phrase that was mentioned frequently. "We know what your programs cost but we don't know what the return on investment is... it would be really cool if you could say it was bottom-line neutral -if you retain the employee and her dependents for 2 years you could expect to avoid certain other comorbid conditions... we know from national data what types of things these kids are expected to have as obese adults in terms of comorbidities, but trying to put a cost to them...would be more of a challenge for us..."

\section{Theme 2: Organizations would like to see tangible evidence of the effectiveness of programs}

Participants reported a desire to learn about the effectiveness of stage 3 programs, and suggested that coverage would not be considered unless programs had demonstrated effectiveness. Long-term outcome was one factor that was stated repeatedly as participants were aware that it is very common for those engaged in weight loss to have weight gain after the programs end. As one participant stated, "We would want to see some kind of evidence that they [programs] work before we would make that decision. If there is a really high failure rate or there's no return on investment, then I think we may not [offer coverage]. We would definitely want to see that they are effective and if they do show proof that they can reduce BMI and the weight, then we would definitely [offer coverage]." Another participant reported, "You need to prove to me that a program would be beneficial and that it would affect the bottom line...you're gonna have to fill the idea, so to speak, and I keep going back to we have to be convinced." One participant recommended that a pilot treatment program with insurer coverage be performed. "They're always looking for ROI so I think you need to probably have a demonstration that comes with ROI. I think that the general employer is getting the wellness and obesity message and they're frustrated in not knowing what to do so they wanna have [an] evidence base as to what really works. So anything that can be documented as a proof study will help."

\section{Theme 3: Participants wanted to help, and felt some social responsibility for providing access to treatment, but were unaware that groups existed}

BOth insurers and employers were aware of the childhood obesity epidemic, and were also aware that treatment was necessary. However, participants were generally unfamiliar with the staged approach to treatment recommended by the Expert Committee (8), and were not familiar with the stage 3 programs available in their area. One participant captured this perfectly when he stated, "Because it's never come to my attention, prior to talking to you... that pediatric obesity wasn't something that would be covered under health insurance. It's just not something I ever thought about." Another participant stated, "I've never had anyone ask about that; it's just way off our radar." Several participants alluded to the social 
responsibility that some employers may experience. "What matters most to your leadership -is it dollars or doing the right thing? We've heard across the board it's doing the right thing, but dollars have to figure into that." Several participants recommended approaching self-insured employers initially and appealing to their sense of social responsibility. One participant stated, "For the development of these programs in my opinion what you need to do is find self-insured employers that are invested in the community, and take the approach that they do things because it's the right thing to do to get these types of programs."

\section{Theme 4: Participants were interested in covering programs if they could see a direct improvement in employee (parent) performance}

Interestingly, both insurers and employers felt that coverage could potentially be leveraged if improvement in parent (employee) health and/or performance could be demonstrated. Participants often used terms such as "absenteeism," "presenteeism," and "productivity" when talking about key indicators of employee performance. To summarize this general theme, one participant stated, "Clearly, healthier individuals are a more productive work force. That's literature; those with large unmet needs that don't visit the doctor or miss their medications, etc, are less productive at work, so from [an] employer or tax payer standpoint, that's why basic investment and public health are a wise investment." Participants also acknowledged the connection between an employee's health and their child's health. As one participant stated, "It really is our goal as an employer to provide the broadest health care coverage we possibly can for the employee's entire family, because we do understand that whether your family is healthy or not is going to have an impact on how productive you are and from time to time with kids, too." Another participant stated, "We believe a well employee is a more productive employee. We believe that a well dependent creates a more productive employee." Participants reported that it is crucial to provide data on employee performance improvements which may result from pediatric weight management treatment. One participant stated, “...we focus on data quite a bit so that's important to our employersunderstanding the burden within their own organization... their absence days, their productivity, their disabilities...."

\section{Theme 5: Participants were unsure whether treatment should be covered under medical insurance, employee assistance/wellness programs, personal responsibility, or some other option}

When presented with possible scenarios for coverage schemes for stage 3 treatment for dependents (e.g., through employee assistance or wellness programs versus traditional medical coverage), insurers and employers were unsure of where this treatment coverage would best fit. Uncertainty was voiced regarding whether group-based childhood obesity treatment programs constituted medical interventions or were primarily educational in nature. As one participant stated, "It's going to be what you're doing, whether it's considered truly medical treatment or educational servicing and how it's provided and who provides it, is going to be very critical to whether or not it's going to be covered by a health plan." Another participant asked, "...is this medical treatment or is this educational treatment? Health plans are not education programs. We are not set up to be that or to finance that." Interestingly, several participants also brought up "personal responsibility" when asked about the topic of coverage, as exemplified by the comment, "In certain respects there are 
some lines between personal responsibility and the entitlement attitude also-where does one start and where does the one other end? So I guess I would want to look at that also. It's just like ok, if someone wants a gym membership to remain fit and healthy-is that the responsibility of the health plan to cover that? Or is that personal responsibility? I mean in my mind I would put that on the personal responsibility side." Finally, participants referenced the obesogenic environment, "This is not medical care. It's the whole darn environment we are in, culturally, everything," and the responsibility of the community in obesity prevention and treatment. "...it seems like everybody is playing this "who is ultimately responsible'...what are we going to do with pediatric obesity as a community [is] much bigger than just trying to dissect out who's paying what." The following comment highlighted the challenging issue of assigning responsibility to a sole entity, "The thing that happens in terms of services is when you describe it as a community based program, people start to think of what covers services in the community and therefore uncovered by the medical side of the insurance. So you need to have a defining line whether you are on the medical side of the community or a service side."

\section{Theme 6: The process of adding a new covered benefit can be confusing and arduous, and varies a great deal from organization to organization}

Insurers in particular acknowledged the difficulty in determination of a new covered benefit and its components. Procedures to add a new covered benefit varied depending upon whether the entity was public (such as Medicaid) or a private company, but also varied within these categories. "We have to look at medical criteria but we have to take into consideration how much money we have to spend... also, there are state regulations we have to follow and federal laws we have to follow, so we look at all those things." Every participant, however, reported that even with a known governing structure and chain-ofcommand, new benefits have been added for a variety of unpredictable reasons, including new medical evidence, change in state or federal laws, public outcry, or less tangible factors. Employer decisions are also based on multiple factors. "Employers make some of these purchase decisions based on a multitude of issues - the employer size, the employer bargaining groups such as unions... and brokers who heavily influence their decisionmaking." One employer's benefits director stated, "I make recommendations based on what I know about the trends that are happening in health care and benefits arenas, and what I hear from the employees, as well, when I'm out and about in explaining things."

\section{Discussion}

The current qualitative study adds a great deal to the literature on barriers to the proliferation of Stage 3 programs, as reported by employer and insurers - two key stakeholder groups. The findings indicate that barriers were noted to adding coverage of stage 3 family based behavioral group treatment of pediatric obesity. Not surprisingly, cost was a primary barrier. The annual cost of adult obesity to United States public and commercial insurers has been estimated to be approximately $\$ 147$ billion (15). Children and adolescents constitute nearly $15 \%$ of large employers' health care costs (16), and in light of the economic downturn occurring during the study period, containing costs was a top-of-mind concern for those interviewed. The ability of a proposed treatment program to demonstrate return on 
investment or at the minimum, cost neutrality, was favored. Treatment program leaders, who are often housed in academic medical centers, should gain assistance from their health outcomes and health economics colleagues to develop a business case for stage 3 programs, including costs associated with obese dependents, costs of the treatment program and associated potential future cost savings. Demonstrated effectiveness, the second major theme, is congruent with known insurer practices such as literature reviews and consultation of national medical directors and guidelines (17) prior to establishment of new covered benefits. Many stage 3 programs track their outcomes and should package these in an understandable way for presentation to insurer and employer groups. Additionally, leaders should educate these stakeholders on evidence-based treatment recommendations and demonstrate their program's alignment with them. This engagement process will address the study's third major theme: lack of awareness of the existence of stage 3 treatment programs. The potential increased investment in the community felt by self-insured employers may make this group a prime target for engagement on coverage issues. In response to the study's fourth major theme, that participants wanted to see direct improvements in employee performance as a result of their involvement in their child's obesity treatment, program leaders should track and highlight improvements in parent/guardian body mass index and other health and performance indicators as possible. For example, obese children have been noted to be absent from school more often (18), and to have nearly twice as many physician office visits than their non-obese peers (19), both of which may necessitate parental absence from work. Achievement of healthier weight status may lead to fewer child and parental absences. Uncertainty about what sector/s are involved in treatment and treatment coverage was expressed by participants as the study's fifth major theme. Program leaders should clarify that their treatment programs, through evidence-based behavior modification strategies, aim to decrease obesity and the known medical and psychological comorbidities that accompany it, and are not solely educational in nature. Further, leaders should emphasize that these stage 3 programs are typically provided by medical, behavioral, nutrition and physical fitness experts housed in pediatric tertiary care centers, further differentiating these programs from those which could be provided by community service organizations. Finally, in response to the study's sixth major theme, that new benefit determination is a confusing, arduous process which varies from organization to organization, program leaders should seek to learn local insurer and employer benefit determination practices, and be prepared to adapt their presentations to the information needs of different stakeholders.

Strengths of the study are that it is among the first to examine and report the perspectives of both health insurers and employers on childhood obesity treatment coverage, an issue with significant public health and economic consequences, and that the study was conducted using structured face to face interviews and standardized and accepted evaluation techniques. Limitations of the study include its small geographic area, which may limit the generalizability of its findings, and a small number of participants. The perspectives of insurers and employers on the issue of coverage of stage 3 pediatric weight management programs may differ, and those conducting future qualitative studies may want to analyze the comments of each stakeholder group separately. 


\section{Conclusions}

Future efforts should be directed toward examining and defining positive health and workplace productivity outcomes for parents enrolled in stage 3 treatment family based behavioral groups, and on working with key stakeholders to create presentations which include responses to the themes; in essence, giving these stakeholders what they want to know to improve the coverage of stage 3 pediatric obesity treatment programs. As Dietz et al. state, "Health plans are natural leaders and partners in efforts to reduce overweight among children and adolescents" (20). Importantly for the authors, when asked to indicate their willingness to meet with other insurers and employers on the issue of coverage for pediatric obesity treatment, all participants responded affirmatively. Several group meetings have subsequently been held and an ongoing commitment is being secured to further explore the possibilities for local coverage of family-based behavioral group interventions for the treatment of childhood obesity.

\section{Acknowledgments}

We thank all of our participants. We thank Renee VanErp for her editing assistance.

Funding agencies: Health Care Foundation of Greater Kansas City, National Institutes of Health to the second author (DK068221).

\section{References}

1. Ogden CL, Carroll MD, Curtin LR, et al. Prevalence of high body mass index in US children and adolescents, 2007-2008. JAMA. 2010; 303:242-249. [PubMed: 20071470]

2. Nader PR, O'Brien M, Houts R, et al. for the National Institute of Child Health and Human Development Early Child Care Research Network. Identifying risk for obesity in early childhood. Pediatrics. 2006; 118:e594-e601. [PubMed: 16950951]

3. Whitaker RC, Wright JA, Pepe MS, et al. Predicting obesity in young adulthood from childhood and parental obesity. N Engl J Med. 1997; 337:869-873. [PubMed: 9302300]

4. Freedman DS, Khan LK, Dietz WH, et al. Relationship of childhood obesity to coronary heart disease risk factors in adulthood: the Bogalusa Heart Study. Pediatrics. 2001; 108:712-718. [PubMed: 11533341]

5. Gortmaker SL, Must A, Perrin JM, et al. Social and economic consequences of over-weight in adolescence and young adulthood. N Engl J Med. 1993; 329:1008-1012. [PubMed: 8366901]

6. Sargent JD, Blanchflower DG. Obesity and stature in adolescence and earnings in young adulthood. Arch Pediatr Adolesc Med. 1994; 148:681-687. [PubMed: 8019620]

7. Han E, Norton EC, Stearns SC. Weight and wages: fat versus lean paychecks. Health Econ. 2009; 18:535-548. [PubMed: 18677723]

8. Barlow SE, the Expert Committee. Expert committee recommendations regarding the assessment, prevention and treatment of child and adolescent overweight and obesity: summary report. Pediatrics. 2007; 120:S164-S192. [PubMed: 18055651]

9. Oude-Luttikhuis H, Baur L, Jansen H, et al. Interventions for treating obesity in children (review). Cochrane Library. 2009; 1:1-187.

10. Whitlock EP, O'Connor EA, Williams SB, et al. Effectiveness of weight management interventions in children: a targeted systematic review for the USPSTF. Pediatrics. 2010; 125:e396-e417. [PubMed: 20083531]

11. United States Preventive Services Task Force. Screening for obesity in children and adolescents: US preventive services task force recommendation statement. Pediatrics. 2010; 125:361-367. [PubMed: 20083515] 
12. Lee JS, Sheer JLO, Lopez N, et al. Coverage of obesity treatment: a state-by-state analysis of Medicaid and state insurance laws. Public Health Rep. 2010; 125:596-604. [PubMed: 20597460]

13. [May 6, 2012] Alliance for a Healthier Generation. Available at: http:// www.healthiergeneration.org/healthcareprofessionals.aspx?id=3287.

14. Morgan, DL.; Krueger, RA. The focus group kit. SAGE Publications; Thousand Oaks, CA: 1998.

15. Finkelstein EA, Trogdon JG, Cohen JW, et al. Annual medical spending attributable to obesity: payer-and service-specific estimates. Health Aff (Millwood). 2009; 29:w822-w831. [PubMed: 19635784]

16. [May 6, 2012] Mercer Health and Benefits Consulting. National survey of employer-sponsored health plans: 2005 survey report. Mercer Health and Benefits Consulting 2006. National Business Group on Health. Childhood Obesity: It's Everybody's Business. Washington DC. National Business Group on Health, September 2009. Available at: http://www.businessgrouphealth.org/ preventive/topics/child_obesity.cfm\#18.

17. [May 6, 2012] Milliman Care Guidelines ${ }^{\circledR}$. Available at: http://www.careguidelines.com/.

18. Geier AB, Foster GD, Womble LG, et al. The relationship between relative weight and school attendance among elementary schoolchildren. Obesity. 2007; 15:2157-2161. [PubMed: 17712135]

19. Thomson Reuters. [May 6, 2012] Childhood obesity: Medicaid versus private insurance. Available at: http://home.thomsonhealthcare.com/Presentations/view/?id=2187.

20. Dietz W, Lee J, Wechsler H, et al. Health plans' role in preventing overweight in children and adolescents. Health Aff (Millwood). 2007; 26:430-440. [PubMed: 17339670] 


\section{TABLE 1}

Structured interview questions presented to medical directors (insurers) and benefits directors (employers)

\begin{tabular}{|c|c|}
\hline Question & Key benefits issue \\
\hline How are insurance coverage decisions made in your organization? & Identifying decision-makers \\
\hline What benefits do those you serve care most about? & Primary benefits requests \\
\hline How does health impact performance in those with which you work? & Links between health and performance \\
\hline $\begin{array}{l}\text { What is your perspective on the claim that insurers would offer obesity treatment coverage if } \\
\text { employers requested it, and employers would request obesity treatment coverage if insurers } \\
\text { offered it? }\end{array}$ & Knowledge of available coverage \\
\hline $\begin{array}{l}\text { Does the fact that children are not directly responsible for healthcare coverage purchase } \\
\text { decisions affect the coverage of pediatric obesity treatment programs? }\end{array}$ & Impact of dependents on coverage decisions \\
\hline Should treatment be a covered benefit, an out of pocket expense or another option? & Options for treatment coverage \\
\hline Does group-based (versus individual) treatment make a difference? & Options for treatment coverage \\
\hline $\begin{array}{l}\text { Does your organization cover wellness expenses (gym membership, Weight Watchers, etc)? } \\
\text { Would this coverage extend to a treatment program? }\end{array}$ & Options for treatment coverage \\
\hline Do you plan changes to benefits coverage based on the Affordable Care Act? & Future plans to modify coverage \\
\hline Can you offer other advice? & \\
\hline
\end{tabular}

